\title{
A Threshold-like Effect on the Interaction Between Hydrological Connectivity and Dominant Plant Population in Tidal Marsh Wetlands
}

\author{
Jiakai Liu ${ }^{1}$, Ying Liu $^{1}$, Lumeng Xie ${ }^{1}$, Liyi Dai ${ }^{1}$, Zhenming Zhang ${ }^{1}$, and Mingxiang Zhang ${ }^{1}$ \\ ${ }^{1}$ Beijing Forestry University
}

May 19, 2020

\begin{abstract}
Tidal marsh wetlands in the Yellow River Delta provide valuable eco-services to the local population and global ecology. However, this area is suffering from serious degradation under the stresses of social development and climate change. Hydrological connectivity, a new framework in hydrology and ecology, has been proposed as the main factor affecting the ecological processes in coastal wetlands; however, its role in hydrology-soil-vegetation interactions remains unclear. In this study, the researchers parametrically quantified the hydrological connectivity in the tidal marsh wetlands and analyzed its relationship with Phragmites australis, one of the dominant species in this area. Our results showed threshold-like effects on the interaction between hydrological connectivity and P. australis on the plot scale. When biomass is lower than $2.2 \mathrm{~kg} / \mathrm{m} 2$, the population density and structure size were found to increase with hydrological connectivity. When the biomass is higher than the threshold, the plots disconnected hydrologically because of high water consumption. Compared with soil chemistry, salinity, and water soil content, hydrological connectivity in the surface soil layer is more strongly linked to the plant traits and spatial structure in the tidal marsh wetlands due to the narrow ranges of other variables. Based on the authors' analysis, the researchers do not recommend dense plantation of P. australis, especially near the freshwater sources in the tidal marsh, because of its high reproduction ability and competitive nature, which may cut the freshwater connectivity off, lowering the richness of plant species and habitat diversity.
\end{abstract}

A Threshold-like Effect on the Interaction Between Hydrological Connectivity and Dominant Plant Population in Tidal Marsh Wetlands

Jiakai Liu1, Ying Liu1, Lumeng Xie1, Shiqiang Zhao1, Yili Dai, Zhenming Zhang1*, Mingxiang Zhang1*

1 School of Nature Conservation, Beijing Forestry University, Beijing, CN

Jiakai Liu:timberfield1991@163.com

*Corresponding authors:

Mingxiang Zhang:zhangmingxiang@bjfu.edu.cn

Zhenming Zhang:zhenmingzhang@bjfu.edu.cn

Highlights

- Population density and structure size increase along with hydrological connectivity.

- Population with biomass higher than $2.2 \mathrm{~kg} / \mathrm{m}^{2}$ has been determined to have lower hydrological connectivity.

- Soil salinity and soil chemistry have narrow ranges in the tidal marsh.

- Large area restoration of $P$. australis may cut freshwater connection off. 


\section{Abstract}

Tidal marsh wetlands in the Yellow River Delta provide valuable eco-services to the local population and global ecology. However, this area is suffering from serious degradation under the stresses of social development and climate change. Hydrological connectivity, a new framework in hydrology and ecology, has been proposed as the main factor affecting the ecological processes in coastal wetlands; however, its role in hydrology-soil-vegetation interactions remains unclear. In this study, we parametrically quantified the hydrological connectivity in the tidal marsh wetlands and analyzed its relationship with Phragmites australis , one of the dominant species in this area. Our results showed threshold-like effects on the interaction between hydrological connectivity and $P$. australis on the plot scale. When biomass is lower than $2.2 \mathrm{~kg} / \mathrm{m}^{2}$, the population density and structure size were found to increase with hydrological connectivity. When the biomass is higher than the threshold, the plots disconnected hydrologically because of high water consumption. Compared with soil chemistry, salinity, and water soil content, hydrological connectivity in the surface soil layer is more strongly linked to the plant traits and spatial structure in the tidal marsh wetlands due to the narrow ranges of other variables. Based on the authors' analysis, the researchers do not recommend dense plantation of $P$. australis, especially near the freshwater sources in the tidal marsh, because of its high reproduction ability and competitive nature, which may cut the freshwater connectivity off, lowering the richness of plant species and habitat diversity.

Keywords: Tidal marsh wetlands; Hydrological connectivity;Phragmites australis ; Threshold-like effect; Wetland restoration

\section{Introduction}

Tidal marsh wetlands have been providing valuable ecological services (Barbier, 2013; Zhao et al., 2016), such as coastal protection (Costanza et al., 2008), habitat support for multiple species (Kelly and Condeso, 2017), and carbon stoke (Van de Broek et al., 2019). Moreover, it is also considered as one of the most vulnerable ecosystems, suffering from severe degradation brought about by the stresses from both climate change and human activities in the last few decades (Morris et al., 2002; Wiegand and Moloney, 2014). In China, rapid urbanization and economic growth have turned about $51 \%$ of their coastal wetland areas into other land types (An et al., 2007). Apart from that, agriculture and industry development have also led to seawater pollution and petroleum hydrocarbon contamination (Huang et al., 2017; Meng et al., 2014). Restoring and protecting the coastal wetlands became one of the priorities in the comprehensive environmental improvement plans not only of the Chinese government (http://www.cnwm.org.cn/wildren/index.asp) but also of other countries worldwide (Newton et al., 2012; Thorne et al., 2018).

Ecological restoration and protection are based on key processes and should follow the basic ecological laws, which require guidance from theoretical research. Hydrological connectivity is considered the fundamental factor (Hiatt and Passalacqua, 2015; Keesstra et al., 2018) that connects all the ecological elements, which in turn affects other ecological processes (Perkin et al., 2015) occurring in the tidal marsh wetlands. Previous studies in Saint Lawrence River estuary in North America showed that water depth can affect the native species distribution, and enhancing hydrological connectivity by digging channels can increase both density and cover rates of Carex ,Juncus , Eleocharis, and Cyperus plants (Farrell et al., 2010). In the west coast of the Pacific Ocean, studies also showed that changes in (ground) water depth can affect the traits of dominant species, such as Phragmites communis , Suaeda salsa, and Tamarix chinensis (Cui et al., 2010; Guan et al., 2017; Hua et al., 2012; Li et al., 2019). However, as shown in the previous text, several studies lacked a parameterization method for this new framework, and consequently, the relation remains unclear. Although there are several parametrization methods already developed, the concepts and ecological meanings of hydrological connectivity vary depending on the scales, environment backgrounds, and study aims (Bracken et al., 2013; Bracken and Croke, 2007). Most of the existing parametrization methods are developed based on forest basins, which aim to quantify the correlation between hydrological processes, such as water yield, and hydrological connectivity. Consequently, those indices can hardly be used for ecology studies in coastal areas. 
Recently, several studies have attempted to find the proper methods to parametrize hydrological connectivity in coastal wetlands for further eco-hydrology analysis. Hydrological connectivity in the coastal wetlands is mainly determined by the tidal creek morphology, soil water content, and topography. A directional connectivity index based on topography (the presence of surface water) applied in Everglades, South Florida, USA, revealed that the loss of hydrologic connectivity occurs more rapidly and is a more sensitive indicator of declining ecosystem function than other parameter (e.g., habitat area) used previously (Larsen et al., 2012). Another study in the Yellow River Delta, China, quantified the hydrological connectivity based on the microtopography and soil water content in the surface soil layer where distinct differences among different wetland classes were found (Liu et al., 2019). A follow-up research also reported that the distribution of species and biomass in high salinity areas are affected by hydrological connectivity (Liu et al., 2020; Liu et al., 2020). As several other studies found that the distribution and cover rate of plant species are also influenced by the distribution and morphology of tidal creeks (Fleri et al., 2019; Wu et al., 2020), studies examining the relationship between dominant species population structure and hydrological connectivity remain to be limited.

The Yellow River Delta is one of the important international wetlands located in China. It is located at the east economic center of China, and it is also a pivot airport of bird migration routes, East Asia-Australia Flyway, specifically. Thus, this area holds the balance between economic development and ecological safety (Wang et al., 2016), both regionally and globally. The conflict between wetland conservation and soil development is also looming. From 1986 to 2005, around $65.09 \mathrm{~km}^{2}$ tidal marsh wetlands were converted to farmland (Huang et al., 2012), and the condition of the remaining wetlands has been seen to be deteriorating (Qing et al., 2010; Zang et al., 2017), with several ecological issues, such as patch isolation, soil pollution, and decreasing biodiversity (Li et al., 2019; Ma et al., 2019; Wang et al., 2012). In order to resolve the conflict, the Chinese government has been increasing its investment and launched several projects in the last 5 years to help in the conservation of the tidal marsh wetlands. The local governments are also seeking cooperation from institutions to manage the Yellow River Delta more efficiently from a hydrological perspective.

Phragmites australis is one of the most dominant species in the Yellow River Delta, which provides important ecological functions in the ecosystem, such as constructing habitats for migration bird populations on the East Asia-Australasia Flyway (Li et al., 2019) and regulating biochemical cycle (Huang et al., 2012). Multiple projects carried out at several sites in the tidal marsh wetlands since 2001 also seek to restore wetlands using this dominant species (Wang et al., 2012). In this study, the researchers aim to reveal the interaction between the $P$. australis population and hydrological connectivity, through the following steps: (1) parameterizing the hydrological connectivity of each plot, (2) grouping the plots based on plant traits and spatial structures, respectively, (3) comparing the difference of environmental factors and plant traits/spatial structures among different groups, and (4) analyzing the interactions among them.

\section{Material and methods}

\subsection{Experiment design}

Yellow River Delta, considered as the world's youngest neoteric delta in a temperate zone, is located in the southwestern part of Bohai Bay (Zhang et al., 2017). New coastal wetlands were seen to form quickly since 1976 (Wang et al., 2016); this could be attributed to channel changes and large amounts of sediments in the estuary area coming from the Yellow River. As shown in Fig. 1, this experimental tidal marsh wetland is located at the northern part of the modern Yellow River channel, and the shoreline is on the northeast edge of this wetland. The dominant plant species are Phragmites australis, Suaeda salsa, and Tamarix chinensis (Liu et al., 2020; Liu et al., 2020). This experiment was conducted from July to August of 2018, and the sampling period was from 4 am to 8 am to avoid the influence of tides. This is a period of low tide according to the Chinese National Sea Service (www.cnss.com.cn), and this is the only time the researchers can access the whole experimental area.

The researchers set five east-west transects every $700 \mathrm{~m}$, and each of them is approximately measuring 1,500 $\mathrm{m}$ long. Then, six experimental plots were randomly set in each transect. The plot size is $1 \mathrm{~m} \times 1 \mathrm{~m}$, 
and the soil water content in the rhizosphere layer $(0-20 \mathrm{~cm})$ of the experimental plots and eight adjacent $1 \mathrm{~m} \times 1 \mathrm{~m}$ patches (Mckee and Mcmorris, 1999) was measured by time domain reflectometry (TDR)-based potential soil moisture measuring instrument (TRIME-PICO TDR, IMKO Co. Ltd, Germany). Moreover, in each plot, the researchers also took one ring-cut sample and a soil sample. The soil samples were air-dried and crushed to pass through a 2 -mm steel mesh before subsamples of $50 \mathrm{~g}$ were ground in a mortar to pass through a $0.25-\mathrm{mm}$ sieve. Then, the soil total nitrogen (TN), total phosphorus (TP), and soil salinity of the sieved samples were then determined. TN concentrations of soil samples were measured using the Kjeltec method (Zhang et al, 2019), TP was determined colorimetrically after wet digestion with $\mathrm{H}_{2} \mathrm{SO}_{4}$ plus $\mathrm{HClO}_{4}$ (Xiao et al, 2012), and salinity was measured using soil electrical conductivity (Feng et al., 2017).

Plant data were also recorded. First, the researchers set the north-east corner of each plot as the coordinate origin; then, the coordination, height, and basal stem diameter of each $P$. australis were noted; and finally, all were harvested and weighed immediately in the field using digital portable scales (SPX622ZH, NAVIGATOR ${ }^{\mathrm{TM}}$, OHAUS Co. Ltd, USA). They were later kept in sealed labeled bags. The fresh materials were dried at $60{ }^{\circ} \mathrm{C}$, and the samples were weighed every $24 \mathrm{~h}$ until the weights remained the same.

\subsection{Hydrological connectivity parameterization}

In this current study, the researchers used the over-field capacity method (OFCI) developed in the Yellow River Delta based on the surface soil water condition and graph theory (Liu et al., 2019), and then the Point Scale Hydrological Index (PHCI) and Degree Centrality Index (Degree) were calculated by parametrizing the hydrological connectivity. First, the field capacity was calculated as:

$z=\left[\left(w_{s}-w_{n}\right)-\left(w_{s}-w_{d}\right)\right] / w_{n}(1)$

where $z$ is the field capacity $(\mathrm{g} / \mathrm{g}) ; w_{s}$ is the saturated soil mass $(\mathrm{g}) ; w_{d}$ is the sample mass $(\mathrm{g})$ after 2-day drainage under non-evaporative conditions (Cassel et al., 1986); and $w_{n}$ is the net soil mass (g) of the ring-cut sample. The water soil content and the field capacity of all the cells were calculated based on the ring-cut samples and inverse distance weighted interpolation.

The OFCI method was improved from ICSL (Liu et al., 2019; Liu et al., 2019) based on water soil content and graph theory. The (dis)connection of each cell was determined by field capacity. For plots with water soil contents higher than the field capacity, the values will be replaced by 1 ; otherwise, 0 ; calculated as:

$$
\begin{array}{cc}
I_{\mathrm{ij}}=\{ & \\
w_{\mathrm{ij}}-z_{\mathrm{ij}} & \text { if } w_{\mathrm{ij}}>z_{\mathrm{ij}} \\
0 & \text { else }
\end{array}
$$

where $w_{i j}$ is the water soil content of the plot $V_{i j}$ and $z_{i j}$ is the field capacity of plot $V_{i j}$. All plots with value higher than 0 are connected nodes. The edge of these pairs is the hydrological distance between $V_{i j}$ and $V_{r c}$, which can be calculated as:

$H D\left(V_{\mathrm{ij}}, V_{\mathrm{rc}}\right)=I_{\mathrm{ij}}-I_{\mathrm{rc}}(3)$

And the Degree Centrality Index is the number of the connected patches around the target plots, whereas PHCI can be calculated as:

$P H C I=\sum \mathrm{HD}(4)$

where if PHCI $<0$, then it means that the soil water potential of the target plot is relatively low, and it can get water supply from the connected patches and vice versa. Higher PHCI absolute values and degree indices indicate a stronger hydrological connectivity. All the indices were calculated using the self-writing code in MATLAB software version 2019b.

\subsection{Plant traits and spatial structure}

The researchers used two metrics to demonstrate the traits and spatial structure of $P$. australis . The plant density $\left(\right.$ stems $\left./ \mathrm{m}^{2}\right)$, mean height $(\mathrm{cm})$, mean stem diameter $(\mathrm{cm})$, and biomass $\left(\mathrm{kg} / \mathrm{m}^{2}\right)$ of each plot 
were used to quantify the plant traits. Furthermore, the researchers constructed a Delaunay triangulation network and relevant parameters to estimate the spatial structures (Zenner, 2005; Liu et al., 2018; Zenner and Hibbs, 2000). Firstly, the network of each plots was established based on the coordination and heights of the individuals, and then the triangle numbers, mean triangle perimeters $(\mathrm{cm})$, mean triangle $\operatorname{area}\left(\mathrm{cm}^{2}\right)$, and Structure Complexity Index (SCI) of each network were calculated. The four parameters indicate the size, connection, distribution model, and complexity of the spatial structure. The SCI is the ratio of the three-dimensional total side lengths and projected total side lengths, calculated as:

$S C I=\mathrm{SCI}^{*} / \sum_{i=1}^{N-1} \sqrt{\left(x_{i}-x_{i+1}\right)^{2}+\left(y_{i}-y_{i+1}\right)^{2}}(5)$

where $S C I^{*}$ is the sum of the three-dimensional side lengths, defined as:

$\mathrm{SCI}^{*}=\sum_{i=1}^{N-1} \sqrt{\left(x_{i}-x_{i+1}\right)^{2}+\left(y_{i}-y_{i+1}\right)^{2}+\left(z_{i}-z_{i+1}\right)^{2}}(6)$

where $N$ is the number of individuals, $x_{i}$ and $y_{i}$ are the spatial coordinates of individuals $i$, and $z_{i}$ is the height of individuali. The lower bound for the SCI is 1, which means all the plants have the same height. The spatial networks and parameters are calculated based on a field study data in $\mathrm{R}$ software version 3.6 .3 (https://www.r-project.org/).

\subsection{Statistic analysis}

In the Results section, the researchers used PCA (Jolliffe, 1986; Ding and He, 2004) and K-means clustering (Yadav and Sharma, 2013) to analyze the plant traits and the spatial structure metrics, respectively, and all the plots were then later divided into multiple groups based on the analysis. Then, the plant characteristics and environmental factors were compared to find the differences of both independent factors and response variables. Regression analysis was performed to highlight the interaction between hydrological connectivity and plant traits/spatial structures. In order to compare the impacts of hydrological connectivity with other environmental variables, such as soil chemistry, CCA (ter Braak, 1986) analysis was conducted as explained in the Discussion section, and the researchers also tested the deduction of the threshold-like effect by further grouping the data from the regression analysis. All statistical analyses were conducted using the $\mathrm{R}$ software version 3.6.3.

3 Results

\subsection{Parameterization of hydrological connectivity}

Two indices, PHCI and Degree Centrality Index, were utilized to quantify hydrological connectivity in the inter-tidal marsh on the plot scale. The results, presented in Figure 2, indicate that about $38.09 \%$ of the plots were disconnected, and their Degree Centrality Index and PHCI values were recorded to be at 0 . The PHCI values of all the connected plots were negative, and the average value was at -5.63 , which means that those plots, with relatively lower soil water content and soil water potential, have the ability to get water supply from neighboring areas. Half of the PHCI values were distributed from -1 to 0 , whereas the range is approximately 17.21. The average Degree Centrality Index value of the connected plots was 4.07 , and they were equally distributed based on their change interval ([1,8], for the connected plots). Higher absolute values of PHCI indicate more water supply that the plots can get from the connected patches, and similarly, higher degree values demonstrate that the target plots can get water supply from larger adjacent areas. Moreover, the absolute values of PHCI and Degree Centrality Index are positively correlated $\left(P<0.001, R^{2}=0.51\right.$ ). Thus, in this study, higher absolute values of both indices indicate better hydrological connectivity, which means more water supply.

\subsection{Plant traits and their interaction with hydrological connectivity}

The mean population density, plant height, stem diameter, and biomass of $P$. australis were $11.47 \pm 7.62$ stems $/ \mathrm{m}^{2}, 56.62 \pm 8.77 \mathrm{~cm}, 0.35 \pm 0.13 \mathrm{~cm}$, and $2.73 \pm 2.23 \mathrm{~kg} / \mathrm{m}^{2}$, respectively. Figure $3 \mathrm{~A}$ presents the PCA analysis of plant traits. The first two dimensions account for the $76.08 \%$ of the explainable variance, and the densities, heights, diameters, and biomasses contribute $23.14 \%, 6.14 \%, 22.86 \%$, and $23.93 \%$, respectively. 
These four factors can strongly explain why plant traits and plant height were relatively less important. By combining PCA and cluster analysis, the plots were divided into two groups (Figure 3B), and the clustering coefficient was determined at 0.34 . The density, average height, average diameter, and biomass of each group are given in Table 1 (mean \pm standard error). The average heights of groups $\mathrm{A}$ and $\mathrm{B}$ did not show significant differences $(P=0.320)$. However, the density, mean stem diameters, and biomass of group A were found to be significantly higher than those of the group B (P [?] 0.001). Meanwhile, individuals in group A were determined to be stronger with a denser distribution than that in group B, and they consequently led with a higher biomass.

Different environmental variables could be the most possible cause why plants present differences. Thus, the researchers compared hydrological connectivity, soil salinity, TP, TN, and SWC between the two groups. As shown in Table 2, for plant traits, all the plots in group A were disconnected, and the PHCI and degree indices were significantly different. The soil salinity, TP, TN, and SWC of the two groups did not show any significant difference as well $(P[?] 0.05)$. P. australis in disconnected plots were also found to have higher biomass, which can led to higher evapotranspiration and water consumption, lowering the SWC below the field capacity and subsequently disconnecting the plots.

We did regression analysis in order to specifically reveal the interactions between hydrological connectivity and plant traits, and the results, as presented in Figure 4, demonstrate that for the connected plots (group B), population density $\left(P=0.00 ; R^{2}=0.51\right)$ was found to be positively correlated with degree indices, whereas stem diameter $\left(P=0.001, R^{2}=0.66\right)$ was negatively related to degree indices. Population density was positively related to PHCI absolute values at a $95 \%$ confidence level $\left(P=0.011, R^{2}=0.46\right)$. Plant height and biomass did not show any statistical correlation with neither indices. Population densities have been seen to increase along with hydrological connectivity; this is because sufficient water supply can ensure more stems sprouting from the rhizome; however, because of the limitation brought about by other nutrient and environmental stress, the biomass remains low, and the stem diameters were found to be lower in those plots with more stems. Moreover, combined with the comparison between groups, the interaction presented a threshold-like effect. When the biomass was higher than $3.5 \mathrm{~kg} / \mathrm{m}^{2}, P$. australis disconnected the plot by increasing the water consumption and lowering the SWC below the field capacity, whereas when the biomass was relatively low, better hydrological connectivity increased the number of stems.

\subsection{Spatial structures and their interaction with hydrological connectivity}

The researchers constructed the Delaunay triangulation networks based on the spatial three-dimensional coordinates of individuals in each plot and estimated triangle numbers, mean perimeter, mean area, and SCI to quantify the spatial structure. These four parameters measure the size, closeness, betweenness, and complexity of the structure.

The PCA analysis based on the spatial structure of $P$. australis has been presented in Figure 5A. The first two dimensions account for $72.89 \%$ of the explainable variance, and the contribution of triangle numbers, mean perimeter, mean area, and SCI was at $16.16 \%, 22.49 \%, 12.24 \%$, and $22.01 \%$, respectively. These four factors can strongly explain why the spatial structure and mean perimeter, as well as SCI, were relatively more important. By combining PCA and cluster analysis, the plots were then divided into two groups (Figure 5B), and the clustering coefficient was at 0.37. Spatial structure factors were given in Table 1 (mean + - standard error). The average triangle numbers of group A were significantly more than those in group B $(P<0.001)$, and the SCI value of group A was also significantly higher than that of group B $(P<0.001)$. However, the triangles' mean perimeter $(P=0.578)$ and mean area $(P=0.173)$ between the two groups did not show any statistical difference. Triangle numbers and SCI have illustrated the density and heterogeneity (Liu et al., 2018) of the spatial structure, and the plots in group A have been found to be relatively denser and more heterogeneous spatial structures, which probably led to higher population stability (Zenner and Hibbs, 2000; Zenner et al., 2015).

The environmental variables between the two groups are also shown in Table 2. All the plots in group A were also disconnected, and the absolute values of PHCI and degree indices in group B were significantly 
higher than those in group A. The soil salinity, TP, and TN in the two groups did not show any significant difference $(P[?] 0.05)$, except for SWC in group A, which was found to be significantly lower than that in group B $(P=0.019)$.

A regression analysis was also conducted to specify the interactions between spatial structure parameters and hydrological connectivity indices. As shown in Figure 6, for the connected plots, triangle numbers were positively correlated to Degree Centrality Index $\left(P=0.002 ; R^{2}=0.58\right)$ and absolute values of PHCI $(P$ $\left.=0.005 ; R^{2}=0.52\right)$ at a $95 \%$ confidence level; however, other parameters did not show any statistical correlation with hydrological connectivity indices. Meanwhile, in the disconnected plots, the triangle numbers were more than the connected plots, which means that the interaction between structure size and hydrological connectivity may also have a threshold-like effect. Thus, the researchers have compared the biomass, where it was determined that the biomass of disconnected plots was significantly higher than the connected plots and the positive correlation can be found in the plots with biomass less than about $2.2 \mathrm{~kg} / \mathrm{m}^{2}$.

\section{Discussion}

\subsection{Influence of environment factors on plants}

Hydrology-soil-vegetation interaction is the most fundamental process in coastal wetland ecosystems (Alkarkhi and Alqaraghuli, 2019; Cronk and Fennessy, 2016; Liu et al., 2020), and most of the previous studies highlighted the impacts of soil chemistry on plants. In salt marsh wetlands, soil salinity is one of the main stresses for plant traits, especially for glycophytic species. Increasing soil salinity leads to reduction of species number and biomass (Cui et al., 2009; Gough and Grace, 1998); this is often attributed to the changing soil microorganism community (Paul and Nair, 2008) and declining the photosynthetic carbon assimilation and electron transfer capacities (Hanganu et al., 1999; Lu et al., 2017; Munns, 1993). Combined with the anaerobic environment caused by tidal inundation, plants allocate more energy to resist environmental stresses instead of using it for productive processes (Luo et al., 2016; Spalding and Hester, 2007), and older individuals are observed to be more vulnerable for several species (Touchette et al., 2012). Studies involving $P$. australis also found that higher salinity will increase the content of superoxide dismutase, peroxidase, and catalase in plants, which can cause damage to plants' organisms (Burdick and Konisky, 2003; Xu et al., 2012); this will consequently lower the biomass and plant height. However, it also has a high tolerance to salinity (approximately 40 ppt or $3 \%$ ) by accumulating $\mathrm{Na}^{+}$and $\mathrm{Cl}^{-}$in old organs and reducing water uptake and vacuole compartmentalization of toxic ions (Achenbach et al., 2014; Achenbach et al., 2013). Moreover, the root colonization potential of the strain of plant growth-promoting rhizobacteria could not be hampered with higher salinity in soil (Paul and Nair, 2008).

Hydrology is another key factor for plant growth, and most researches only use (ground) water depth to link hydrology and vegetation, especially for field studies in coastal wetlands (de Szalay, 2004; Hua et al., 2012; Li et al., 2019; Yu et al., 2012). In recent years, researchers realized that hydrological connectivity can also affect plant traits, species distributions, and several other characteristics of the vegetation (Kang and King, 2013; Liu et al., 2020; Paillex et al., 2009; Pringle, 2003). Case studies in the Yellow River Delta showed that the depth of a tidal creek had a strong correlation with the density $\left(P=0.04 ; R^{2}=0.25\right)$ and height $\left(P=0.01 ; R^{2}=0.40\right)$ of $P$. australis $(\mathrm{Wu}$ et al., 2020). The parameters of tidal creeks were also linked to the terrain-based structural and dynamic hydrological connectivity (Dawidek and Ferencz, 2016; Volk et al., 2018) on the horizontal direction. Besides, the distribution of plant species and communities are mainly dependent on soil salinity (Cui et al., 2008; Cui et al., 2010; Liu et al., 2020; Meng et al., 2016). Several field studies also reported that for the communities in high-salinity habitat, such asSuaeda salsa-Phragmites australis and Suaeda salsa-Tamarix chinensis communities in salt marshes, the biomass and plant cover rates are found to increase along with hydrological connectivity in surface soil layers (Liu et al., 2020; Liu et al., 2020).

In this current study, researchers have highlighted the effects of the interactions between hydrological connectivity and plant traits, as well as its spatial structures. We conducted an RDA analysis to estimate the effects of other environmental variables, and the results are shown in Figure 7. For plant traits shown in 
Figure 7A, the first two and three dimensions accounted for $42.60 \%$ and $43.11 \%$ of the explainable variance, respectively, and only the Degree Centrality Index was correlated to the plant traits' matrix at a 95 $\%$ confidence level $(P=0.017)$. For the spatial structures shown in Figure 7B, the first two and three dimensions accounted for $36.87 \%$ and $43.76 \%$ of the explainable variance, respectively, and only SWC was correlated to the plant traits' matrix at a $95 \%$ confidence level $(P=0.032)$. In addition, TN and TP were also reported as determinants for the growth and community succession of $P$. australis (Gonzalez-Alcaraz et al., 2012; Soana et al., 2020) but failed to show significant impacts here. Further analysis showed that TN ranged from $0.11 \mathrm{~g} / \mathrm{kg}$ to $0.26 \mathrm{~g} / \mathrm{kg}$, and TP ranged from $0.41 \mathrm{~g} / \mathrm{kg}$ to $0.70 \mathrm{~g} / \mathrm{kg}$ in the experimental area. A long-term field monitoring study across the whole Yellow River Delta showed that the average TN in surface soil layer $(0-30 \mathrm{~cm})$ was $0.38+-0.21 \mathrm{~g} / \mathrm{kg}$, and the TP was $0.59+-0.91 \mathrm{~g} / \mathrm{kg}$ (Yu et al., 2016). Higher TN content $(0.51 \mathrm{~g} / \mathrm{kg})$ was distributed in the cropland, whereas in the coastal wetlands, TN content was found to be lower than the other sites, but the distribution of TP did not obviously change among different places. Similarly, the soil salinity ranged from $5.22 \mathrm{Ms} / \mathrm{cm}$ to $7.21 \mathrm{Ms} / \mathrm{cm}$ across all the plots. Thus, in the salt marsh wetland in the Yellow River Delta, the narrow ranges and insignificant soil chemistry heterogeneity led to their insignificant effect on $P$. australis.

Furthermore, based on the authors' analysis, researchers also propose a threshold-like effect, that is, when the biomass is relatively low, the increasing hydrological connectivity also increases the stem numbers and spatial structure sizes. In order to verify this conclusion, researchers have conducted a group regression analysis between population density/triangle numbers and hydrological connectivity indices based on biomass. As shown in Figure 8 , in the plots with biomass lower than $2.2 \mathrm{~kg} / \mathrm{m}^{2}$, the population density $(P=0.007$; $\left.R^{2}=0.57\right)$ and triangle numbers $\left(P=0.004 ; R^{2}=0.63\right)$ were positively correlated to the degree indices. Similarly, the PHCI indices also showed a negative correlation with both population density $\left(P=0.002 ; R^{2}=\right.$ $0.67)$ and triangle numbers $\left(P=0.002 ; R^{2}=0.68\right)$. However, the plots with biomass higher than $2.2 \mathrm{~kg} / \mathrm{m}^{2}$ did not show such statistical relation. The results from the control experiments in greenhouses achieved a supportive conclusion for the authors' deduction that the germination of $P$. australis is influenced by the (ground) water depth (Yu et al., 2012); however, the optimum value of the (ground) water depth remains controversial from different references (Shao et al., 2009; Whigham, 2009). The hydrological connectivity indices in this study were estimated based on the soil moisture, which directly correlates to (ground) water depth, but the specific threshold in different environmental backgrounds and its influencing factors remain unclear in either previous studies or this study.

The researchers also found that almost all the plots with biomass higher than $2.2 \mathrm{~kg} / \mathrm{m}^{2}$ were disconnected hydrologically. In these plots, $P$. australis started to affect the hydrological connectivity by decreasing the SWC below the filed capacity, and there may be no free water connected to the target plot from the adjacent area theoretically.

\subsubsection{Ecological functions of population spatial structures}

The spatial structures of plant populations or meta-populations are essential factors that control species dynamics (Liu et al., 2020; Monzeglio, 2007). The results of this study can provide information about inter-species relations and plant responses to environmental stresses (Omelko et al., 2018; Xu et al., 2020). Different spatial structures were also linked to different ecological functions, such as biodiversity (Ahmad et al., 2020; Chi et al., 2019), water yield (Liu et al., 2018), productivity (Wang et al., 2019; Wang et al., 2020), and micro-scale atmosphere conditions (Abdi et al., 2020; Liu et al., 2016). Traditional quantitative ecology has utilized the two-dimensional (usually on the horizontal direction) coordination of individuals to parameterize the structure (Omelko et al., 2018); however, in this current study, the researchers opted to use a three-dimensional parameter, Structure Complexity Index (SCI), based on the coordination and heights of individuals. This method was developed in forests (Zenner and Hibbs, 2000) to compare the structure heterogeneity with tree species dynamics (Zenner, 2005; Zenner et al., 2015), and previous studies also found that SCI was related to several ecological processes, such as shallow sub-surface runoff (Liu et al., 2018). However, there are few studies that have used such three-dimensional methods in herbaceous species studies.

In the Yellow River Delta, based on two-dimensional spatial quantification, P. australis had an aggregated 
distribution in a $1 \mathrm{~m} \mathrm{x} 1 \mathrm{~m}$ scale in the tidal marsh (Liu et al., 2020). Similar results were also found in this study. The average projected area of the structural networks was about $2175.59 \mathrm{~cm}^{2}$ in each plot, which only accounted for about $21.76 \%$ of the sample area. Our regression analysis also showed a significant relation between population structure sizes and hydrological connectivity, but no evidence indicated that the threedimensional structure was correlated with hydrological connectivity. The plant population or community three-dimensional structures link to the ecological functions although it has not attracted much attention yet. The spatial heterogeneity came from different species, age structure, and genetic diversity, which are all essential for ecosystem stability (Perez-Espana and Arregun-Sánchez, 1999; Zhang et al., 2015). On another note, spatial structure with high complexity may also increase habitat diversity and consequently increase species numbers and habitat quality (Hillard et al., 2017; Nicol et al., 2016; Somerville et al., 2017).

\subsubsection{Applications and uncertainty}

Different researchers hold controversial views toward $P$. australis. Several studies consider this species as the footstone or at least a key species for coastal wetland restoration (Huang et al., 2017). The wide range of salinity (Hurry et al., 2013) and inundation (Wang et al., 2017; Yu et al., 2012) tolerance help the population expand and connect habitat patches quickly. However, wide ranges of niche and clonal reproduction also make $P$. australis highly competitive; thus, it lowers plant diversity with its encroachment. As a non-native species, it has displaced native plant species and has widely degraded wetland habitats (Pengra et al., 2007; Tulbure et al., 2007) in North America. In origin, this species is capable of competing with invasive species, such as Spartina alterniflora (Cui et al., 2020), and overplantation or restoration in large areas may also cause ecological issues. Studies in the Yellow River Delta reported that inP. australis- restored areas, the species' richness and Shannon-Wiener index increased at the first few years and then decreased with restored time (Wang et al., 2012). P. australiscan also alter the allocation of the total phosphorus between the plants and the soils in coastal wetlands, affect the above-ground and below-ground mechanisms, as well as carbon cycling (Cui et al., 2019; Martin and Moseman-Valtierra, 2017), and finally change the abiotic environment.

As per the authors' opinion, coastal wetland management and restoration should focus on the ecological processes instead of the components.P. australis is just one component of the ecosystem, and it can be an indicator of either health or degradation of wetlands, but neither a restoration method nor a restoration goal. Ecological processes, such as hydrological connectivity, are drivers of the ecosystem and key for restoration, especially for maintaining the self-sustainability of coastal wetlands. Thus, the current study links process (hydrological connectivity) to the component ( $P$. australis ), which provides a theoretical guidance for managers that the researchers can enhance the surface soil hydrological connectivity to increase the population density of $P$. australis, whereas its large-scale colonization may also block hydrological connectivity. In the coastal wetlands, freshwater availability is the foundation for the vulnerability of plant species (Osland et al., 2014). Hence, researchers do not recommend $P$. australis plantation or restoration around Yellow River and other freshwater channels.

However, this study also keeps several uncertainties that should be highlighted here. First, the authors' hydrological connectivity parameterization method is based on the soil moisture on a horizontal direction, whereas hydrological connectivity has three-dimensional spatial characteristics, and how the vertical connectivity influenceP. australis remains uncertain. Moreover, hydrological connectivity is highly scale-affected, which is the reason why the interactions in larger scales require further experiments. Finally, how static and dynamic factors, such as soil texture (Hu et al., 2020) and tidal movements, influence hydrological connectivity is also crucially important to reveal the mechanism of hydrology-soil-plant interactions, where research gaps still remain.

\section{Conclusions}

In this current study, the researchers found a threshold-like effect on the interaction between hydrological connectivity and $P$. australis on the plot scale. When the biomass was lower than $2.2 \mathrm{~kg} / \mathrm{m}^{2}$, the population density and structure size increased with the hydrological connectivity. However, the hydrological connectivity was observed to decrease dramatically when the biomass was higher than the threshold value, because 
increased water consumption and transpiration due to plant growth lowered the surface water content all the way below the field capacity. Based on the plant traits, all the plots with higher and stronger individuals were disconnected hydrologically, and similarly, based on the spatial structure, all the plots with larger network size were also disconnected. Compared with soil chemistry, salinity, and water soil content, hydrological connectivity in the surface soil layer was more strongly linked to plant traits and spatial structure in the tidal marsh wetlands due to the narrow ranges of the other variables. Finally, in restoration projects, overplantation or large-scale area restoration of $P$. australis is not recommended, especially near freshwater sources in the tidal marsh; this is because of its high reproduction ability and competitiveness, which cuts the freshwater connectivity off and lowers the richness of plant species and habitat diversity.

Acknowledgement

This work was supported by the National Natural Science Foundation of China (41771547) and the National Key R\&D Program of China (2017YFC0505903).

Conflict of Interest Statement

All the authors have no conflict of interests.

References:

Abdi, B., Hami, A. and Zarehaghi, D., 2020. Impact of small-scale tree planting patterns on outdoor cooling and thermal comfort. Sustainable Cities and Society, 56: 102085.

Achenbach, L., Achenbach, L., Brix, H. and Brix, H., 2014. Can differences in salinity tolerance explain the distribution of four genetically distinct lineages of Phragmites australis in the Mississippi River Delta? Hydrobiologia, 737(1): 5-23.

Achenbach, L., Eller, F., Xuan Nguyen, L. and Brix, H., 2013. Differences in salinity tolerance of genetically distinct Phragmites australis clones. AoB PLANTS, 5.

Ahmad, M. et al., 2020. Patterns of plant communities along vertical gradient in Dhauladhar Mountains in Lesser Himalayas in North-Western India. Science of The Total Environment, 716: 136919.

Alkarkhi, A.F.M. and Alqaraghuli, W.A.A., 2019. Chapter 8 - Principal Components AnalysisEasy Statistics for Food Science with R. Academic Press, pp. 125-141.

An, S. et al., 2007. China's Natural Wetlands: Past Problems, Current Status, and Future Challenges. AMBIO, 36(4): 335-342.

Barbier, E., 2013. Valuing Ecosystem Services for Coastal Wetland Protection and Restoration: Progress and Challenges. Resources, 2(3): 213-230.

Bracken, L.J. et al., 2013. Concepts of hydrological connectivity: Research approaches, pathways and future agendas. Earth-Science Reviews, 119: 17-34.

Bracken, L.J. and Croke, J., 2007. The concept of hydrological connectivity and its contribution to understanding runoff-dominated geomorphic systems. Hydrological Processes, 21(13): 1749-1763.

Burdick, D.M. and Konisky, R.A., 2003. Determinants of Expansion for Phragmites australis, Common Reed, in Natural and Impacted Coastal Marshes. Estuaries, 26(2): 407-416.

Cassel, D.K., Nielsen, D.R. and Klute, A., 1986. Field capacity and available water capacity. Method of Soil Analysis Physical \& Mineralogical Methods: 901-926.

Chi, Y., Sun, J., Fu, Z. and Xie, Z., 2019. Spatial pattern of plant diversity in a group of uninhabited islands from the perspectives of island and site scales. Science of The Total Environment, 664: 334-346.

Costanza, R. et al., 2008. The value of coastal wetlands for hurricane protection. Ambio, 37(4): 241-8.

Cronk, J.K. and Fennessy, M.S., 2016. Wetland plants: biology and ecology. CRC press. 
Cui, B., He, Q. and Zhao, X., 2008. Ecological thresholds of Suaeda salsa to the environmental gradients of water table depth and soil salinity. Acta Ecologica Sinica, 28(4): 1408-1418.

Cui, B., Yang, Q., Yang, Z. and Zhang, K., 2009. Evaluating the ecological performance of wetland restoration in the Yellow River Delta, China. Ecological Engineering, 35(7): 1090-1103.

Cui, B., Yang, Q., Zhang, K., Zhao, X. and You, Z., 2010. Responses of saltcedar (Tamarix chinensis) to water table depth and soil salinity in the Yellow River Delta, China. Plant Ecology, 209(2): 279-290.

Cui, L. et al., 2019. Phragmites australis meets Suaeda salsa on the "red beach": Effects of an ecosystem engineer on salt-marsh litter decomposition. Science of The Total Environment, 693: 133477.

Cui, L., Yuan, L., Ge, Z., Cao, H. and Zhang, L., 2020. The impacts of biotic and abiotic interaction on the spatial pattern of salt marshes in the Yangtze Estuary, China. Estuarine, Coastal and Shelf Science, 238: 106717.

Dawidek, J. and Ferencz, B., 2016. Historical Changes of Hydrological Connectivity of Selected Polish Floodplain Lakes. River Research and Applications, 32(9): 1862-1871.

de Szalay, R.B.A.F., 2004. Effects of Hydrology, Herbivory and Sediment Disturbance on Plant Recruitment in a Lake Erie Coastal Wetland. American Midland Naturalist, 151(2): 217-232.

Ding, C. and He, X., 2004. Cluster Structure of K-means Clustering via Principal Component Analysis., 46(4): 414-418.

Farrell, J.M. et al., 2010. Water-level regulation and coastal wetland vegetation in the upper St. Lawrence River: inferences from historical aerial imagery, seed banks, and Typha dynamics. Hydrobiologia, 647(1): 127-144.

Fleri, J.R., Lera, S., Gerevini, A., Staver, L. and Nardin, W., 2019. Empirical observations and numerical modelling of tides, channel morphology, and vegetative effects on accretion in a restored tidal marsh. Earth Surface Processes and Landforms, 44(11): 2223-2235.

González-Alcaraz, M.N. et al., 2012. Storage of organic carbon, nitrogen and phosphorus in the soil-plant system of Phragmites australis stands from a eutrophicated Mediterranean salt marsh. Geoderma, 185-186: 61-72.

Gough, L. and Grace, J.B., 1998. Effects of flooding, salinity and herbivory on coastal plant communities, Louisiana, United States. Oecologia, 117(4): 527-535.

Guan, B. et al., 2017. The ecological adaptability of Phragmites australis to interactive effects of water level and salt stress in the Yellow River Delta. Aquatic Ecology, 51(1): 107-116.

Hanganu, J., Mihail, G. and Coops, H., 1999. Responses of ecotypes of Phragmites australis to increased seawater influence: a field study in the Danube Delta, Romania. Aquatic Botany, 64(3): 351-358.

Hiatt, M. and Passalacqua, P., 2015. Hydrological connectivity in river deltas: The first-order importance of channel-island exchange. Water Resources Research, 51(4): 2264-2282.

Hillard, E.M., Nielsen, C.K. and Groninger, J.W., 2017. Swamp rabbits as indicators of wildlife habitat quality in bottomland hardwood forest ecosystems. Ecological Indicators, 79: 47-53.

Hu, M. et al., 2020. Denitrification rates in tidal marsh soils: The roles of soil texture, salinity and nitrogen enrichment. European Journal of Soil Science, n/a(n/a).

Hua, Y.Y., Cui, B.S., He, W.J. and Liu, Y.L., 2012. Optimum water depth threshold in reed marsh areas of the Yellow River Delta, China. Procedia Environmental Sciences, 13: 1820-1826.

Huang, L. et al., 2012. Two-decade wetland cultivation and its effects on soil properties in salt marshes in the Yellow River Delta, China. Ecological Informatics, 10(Complete): 49-55. 
Huang, X. et al., 2017. Effects of stereoscopic artificial floating wetlands on nekton abundance and biomass in the Yangtze Estuary. Chemosphere, 183: 510-518.

Huang, Y., Zhang, T., Wu, W., Zhou, Y. and Tian, B., 2017. Rapid risk assessment of wetland degradation and loss in low-lying coastal zone of Shanghai, China. Human and Ecological Risk Assessment: An International Journal, 23(1): 82-97.

Hurry, C.R., James, E.A. and Thompson, R.M., 2013. Connectivity, genetic structure and stress response of Phragmites australis: Issues for restoration in a salinising wetland system. Aquatic Botany, 104: 138-146.

Jolliffe, I.T., 1986. Principal component analysis.

Kang, S. and King, S.L., 2013. Effects of Hydrologic Connectivity on Pond Environmental Characteristics in a Coastal Marsh System., 12(3): 568 - 578.

Keesstra, S. et al., 2018. The way forward: Can connectivity be useful to design better measuring and modelling schemes for water and sediment dynamics? Science of The Total Environment, 644: 1557-1572.

Kelly, J.P. and Condeso, T.E., 2017. Tidal marsh restoration stimulates the growth of winter shorebird populations in a temperate estuary. Restoration Ecology, 25(4): 640-649.

Larsen, L.G., Choi, J., Nungesser, M.K. and Harvey, J.W., 2012. Directional connectivity in hydrology and ecology. Ecological applications, 22(8): 2204-2220.

Li, X. et al., 2019. Assessing Changes of Habitat Quality for Shorebirds in Stopover Sites: a Case Study in Yellow River Delta, China. Wetlands, 39(1).

Li, X., Xia, J., Zhao, X. and Chen, Y., 2019. Effects of planting Tamarix chinensis on shallow soil water and salt content under different groundwater depths in the Yellow River Delta. Geoderma, 335: 104-111.

Liu, J. et al., 2016. Dry deposition of particulate matter at an urban forest, wetland and lake surface in Beijing. Atmospheric Environment, 125: 178-187.

Liu, J. et al., 2019. Capturing hydrological connectivity structure of wetlands with indices based on graph theory: A case study in Yellow River Delta. Journal of Cleaner Production, 239: 118059.

Liu, J. et al., 2019. Runoff Response to Soil Moisture and Micro-topographic Structure on the Plot Scale. Scientific reports, 9(1): 2532.

Liu, J. et al., 2020. Hydrological connectivity: One of the driving factors of plant communities in the Yellow River Delta. Ecological Indicators, 112: 106150.

Liu, J. et al., 2020. Multi-scale analysis of hydrological connectivity and plant response in the Yellow River Delta. Science of The Total Environment(702): 134889.

Liu, J., Zhang, Z. and Zhang, M., 2018. Impacts of forest structure on precipitation interception and runoff generation in a semi-arid region in northern China. Hydrological Processes, 32(15): 2362-2376.

Lu, Y. et al., 2017. Effect of NaCl-induced changes in growth, photosynthetic characteristics, water status and enzymatic antioxidant system of Calligonum caput-medusae seedlings. Photosynthetica, 55(1): 96-106.

Luo, F.L., Jiang, X., Li, H. and Yu, F., 2016. Does hydrological fluctuation alter impacts of species richness on biomass in wetland plant communities? Journal of Plant Ecology: rtv065.

Ma, T., Li, X., Bai, J. and Cui, B., 2019. Habitat modification in relation to coastal reclamation and its impacts on waterbirds along China's coast. Global Ecology and Conservation, 17.

Martin, R.M. and Moseman-Valtierra, S., 2017. Plant manipulations and diel cycle measurements test drivers of carbon dioxide and methane fluxes in a Phragmites australis-invaded coastal marsh. Aquatic Botany, 137: $16-23$. 
Mckee, T.A. and Mcmorris, F.R., 1999. Topics in Intersection Graph Theory. Mathematical Gazette, 83(498).

Meng, L., Zhou, S., Zhang, H. and Bi, X., 2016. Estimating soil salinity in different landscapes of the Yellow River Delta through Landsat OLI/TIRS and ETM+ Data. Journal of Coastal Conservation, 20(4): 271-279.

Meng, W.Q., Hu, B.B. and Wang, Z.L., 2014. Coastal Wetland Degradation and its Restoration Planning Incorporating Landscape and Ecological Processes in Tianjin, Northern China. Advanced Materials Research, 955-959: 4123-4132.

Monzeglio, U., 2007. Small-scale spatial pattern and dynamics of experimental plant communities, University of Basel.

Morris, J.T., Sundareshwar, P.V., Nietch, C.T., Kjerfve, B. and Cahoon, D.R., 2002. Responses of coastal wetlands to rising sea level. Ecology, 83(10): 2869-2877.

Munns, R., 1993. Physiological processes limiting plant growth in saline soils: some dogmas and hypotheses. Plant, Cell \& Environment, 16(1): 15-24.

Newton, A., Carruthers, T.J.B. and Icely, J., 2012. The coastal syndromes and hotspots on the coast. Estuarine, Coastal and Shelf Science, 96: 39-47.

Nicol, S. et al., 2016. A management-oriented framework for selecting metrics used to assess habitat- and path-specific quality in spatially structured populations. Ecological Indicators, 69: 792-802.

Omelko, A. et al., 2018. From young to adult trees: How spatial patterns of plants with different life strategies change during age development in an old-growth Korean pine-broadleaved forest. Forest Ecology and Management, 411: 46-66.

Osland, M.J., Enwright, N. and Stagg, C.L., 2014. Freshwater availability and coastal wetland foundation species: ecological transitions along a rainfall gradient. Ecology, 95(10).

Paillex, A., Doledec, S., Castella, E. and Merigoux, S., 2009. Large river floodplain restoration: predicting species richness and trait responses to the restoration of hydrological connectivity. Journal of Applied Ecology, 46(1): 250-258.

Paul, D. and Nair, S., 2008. Stress adaptations in a Plant Growth Promoting Rhizobacterium (PGPR) with increasing salinity in the coastal agricultural soils. Journal of Basic Microbiology, 48(5): 378-384.

Pengra, B.W., Johnston, C.A. and Loveland, T.R., 2007. Mapping an invasive plant, Phragmites australis, in coastal wetlands using the EO-1 Hyperion hyperspectral sensor. Remote Sensing of Environment, 108(1): $74-81$.

Perez-Espana, H. and Arreguin-Sánchez, F., 1999. Complexity related to behavior of stability in modeled coastal zone ecosystems. Aquatic Ecosystem Health and Management, 2(2): 129-135.

Perkin, J.S. et al., 2015. Fragmentation and dewatering transform Great Plains stream fish communities. Ecological Monographs, 85(1).

Pringle, C., 2003. What is hydrologic connectivity and why is it ecologically important? Hydrological Processes, 17(13): 2685-2689.

Qing, L., Wei, L. and Zhaohua, L., 2010. Ecosystem services value assessment of green space in the Yellow River Delta based on RS and GIS. Ecology and Environmental Sciences, 19(8): 1838-1843.

Shao, H. et al., 2009. Understanding water deficit stress-induced changes in the basic metabolism of higher plants - biotechnologically and sustainably improving agriculture and the ecoenvironment in arid regions of the globe. Critical Reviews in Biotechnology, 29(2): 131-151. 
Soana, E., Gavioli, A., Vincenzi, F., Fano, E.A. and Castaldelli, G., 2020. Nitrate availability affects denitrification in Phragmites australis sediments. Journal of Environmental Quality, 49(1): 194-209.

Somerville, G.J., Powles, S.B., Walsh, M.J. and Renton, M., 2017. How do spatial heterogeneity and dispersal in weed population models affect predictions of herbicide resistance evolution? Ecological Modelling, 362: $37-53$.

Spalding, E.A. and Hester, M.W., 2007. Interactive Effects of Hydrology and Salinity on Oligohaline Plant Species Productivity: Implications of Relative Sea-level Rise. Estuaries and Coasts, 30(2): 214-225.

ter Braak, C.J.F., 1986. Canonical Correspondence Analysis: A New Eigenvector Technique for Multivariate Direct Gradient Analysis. Ecology, 67(5): 1167-1179.

Thorne, K. et al., 2018. U.S. Pacific coastal wetland resilience and vulnerability to sea-level rise. Science Advances, 4(2): eaao3270.

Touchette, B.W., Adams, E.C. and Laimbeer, P., 2012. Age-specific responses to elevated salinity in the coastal marsh plant black needlerush (Juncus roemerianus Scheele) as determined through polyphasic chlorophyll a fluorescence transients (OJIP). Marine Biology, 159(10): 2137-2147.

Tulbure, M.G., Johnston, C.A. and Auger, D.L., 2007. Rapid Invasion of a Great Lakes Coastal Wetland by Non-native Phragmites australis and Typha. Journal of Great Lakes Research, 33: 269-279.

Van de Broek, M., Baert, L., Temmerman, S. and Govers, G., 2019. Soil organic carbon stocks in a tidal marsh landscape are dominated by human marsh embankment and subsequent marsh progradation. European Journal of Soil Science, 70(2): 338-349.

Volk, X.K., Gattringer, J.P., Otte, A. and Harvolk-Schöning, S., 2018. Connectivity analysis as a tool for assessing restoration success. Landscape Ecology, 33(3): 371-387.

Wang, C., Wang, Y., Geng, Y., Wang, R. and Zhang, J., 2016. Measuring regional sustainability with an integrated social-economic-natural approach: a case study of the Yellow River Delta region of China. Journal of Cleaner Production, 114: 189-198.

Wang, F. et al., 2019. Effects of planting patterns on yield, quality, and defoliation in machine-harvested cotton. Journal of Integrative Agriculture, 18(9): 2019-2028.

Wang, J. et al., 2020. Joint optimization of irrigation and planting pattern to guarantee seed quality, maximize yield, and save water in hybrid maize seed production. European Journal of Agronomy, 113: 125970.

Wang, M., Qi, S. and Zhang, X., 2012. Wetland loss and degradation in the Yellow River Delta, Shandong Province of China. Environmental Earth Sciences, 67(1): 185-188.

Wang, X. et al., 2012. Vegetative Ecological Characteristics of Restored Reed (Phragmites australis) Wetlands in the Yellow River Delta, China. Environmental Management, 49(2): 325-333.

Wang, X., Zhang, D., Guan, B., Qi, Q. and Tong, S., 2017. Optimum water supplement strategy to restore reed wetland in the Yellow River Delta. PLOS ONE, 12(5): e0177692.

Whigham, D.F., 2009. Seed viability and seed dormancy of non-native Phragmites australis in suburbanized and forested watersheds of the Chesapeake Bay, USA. Aquatic Botany, 91(3): 0-204.

Wiegand, T. and Moloney, K.A., 2014. Handbook of spatial pointpattern analysis in ecology. CRC Press.

$\mathrm{Wu}$, Y. et al., 2020. The size and distribution of tidal creeks affects salt marsh restoration. Journal of Environmental Management, 259: 110070.

Xu, J. et al., 2012. Effect of Ammonia Stress on Physiological and Biochemical Character of Phragmites australis in Constructed Wetland, 2012 Third International Conference on Digital Manufacturing \& Automation, pp. 343-346. 
$\mathrm{Xu}, \mathrm{M}$. et al., 2020. Spatial variation patterns of plant herbaceous community response to warming along latitudinal and altitudinal gradients in mountainous forests of the Loess Plateau, China. Environmental and Experimental Botany, 172: 103983.

Yadav, J. and Sharma, M., 2013. A Review of K-mean Algorithm. International Journal of Engineering Trends and Technology, 4(7): 2972-2976.

Yu, J. et al., 2012. Effects of Salinity and Water Depth on Germination of Phragmites australis in Coastal Wetland of the Yellow River Delta.

Yu, J. et al., 2016. Distribution of carbon, nitrogen and phosphorus in coastal wetland soil related land use in the Modern Yellow River Delta. Scientific Reports, 6(1).

Zang, Z. et al., 2017. Impact of landscape patterns on ecological vulnerability and ecosystem service values: An empirical analysis of Yancheng Nature Reserve in China. Ecological Indicators, 72: 142-152.

Zenner, E.K., 2005. DEVELOPMENT OF TREE SIZE DISTRIBUTIONS IN DOUGLAS-FIR FORESTS UNDER DIFFERING DISTURBANCE REGIMES. Ecological Applications, 15(2): 701-714.

Zenner, E.K. and Hibbs, D.E., 2000. A new method for modeling the heterogeneity of forest structure. Forest Ecology and Management, 129(1): 75-87.

Zenner, E.K., Sagheb-Talebi, K., Akhavan, R. and Peck, J.E., 2015. Integration of small-scale canopy dynamics smoothes live-tree structural complexity across development stages in old-growth Oriental beech (Fagus orientalis Lipsky) forests at the multi-gap scale. Forest Ecology and Management, 335: 26-36.

Zhang, X., Wang, L., Fu, X., Li, H. and Xu, C., 2017. Ecological vulnerability assessment based on PSSR in Yellow River Delta. Journal of Cleaner Production, 167: 1106-1111.

Zhang, Z., Yan, C., Krebs, C.J. and Stenseth, N.C., 2015. Ecological non-monotonicity and its effects on complexity and stability of populations, communities and ecosystems. Ecological Modelling, 312: 374-384.

Zhao, Q. et al., 2016. A review of methodologies and success indicators for coastal wetland restoration. Ecological Indicators, 60: 442-452.

Tables

Table 1 Plant traits and spatial structure parameters of different group (mean \pm standard error)

\begin{tabular}{lllll}
\hline Group & Parameters & Parameters & Parameters & Parameters \\
\hline Traits & Density $\left(\mathrm{stems} / \mathrm{m}^{2}\right)$ & Height $(\mathrm{cm})$ & Diameter $(\mathrm{cm})$ & Biomass $\left(\mathrm{kg} / \mathrm{m}^{2}\right)$ \\
A & $18.57 \pm 9.32$ & $55.37 \pm 7.56$ & $0.45 \pm 0.16$ & $5.26 \pm 1.93$ \\
B & $7.93 \pm 4.10$ & $51.23 \pm 9.26$ & $0.30 \pm 0.08$ & $1.47 \pm 0.88$ \\
Structure & T-Numbers & T-Perimeter $(\mathrm{m})$ & T-Area $\left(\mathrm{cm}^{2}\right)$ & SCI \\
A & $33.00 \pm 14.00$ & $0.98 \pm 0.24 \mathrm{~m}$ & $108.74 \pm 31.20$ & $1.64 \pm 0.05$ \\
B & $9.25 \pm 6.91$ & $1.11 \pm 0.49$ & $176.24 \pm 103.58$ & $1.25 \pm 0.13$ \\
\hline
\end{tabular}

Table 2 Environmental variables of different group (mean \pm standard error)

\begin{tabular}{lllll}
\hline Environmental variables & Based on traits & Based on traits & Based on structure & Based on structure \\
\hline & Group A & Group B & Group A & Group B \\
PHCI & $0.00 \pm 0.00$ & $-5.29 \pm 7.49$ & $0.00 \pm 0.00$ & $-4.62 \pm 7.21$ \\
Degree & $0.00 \pm 0.00$ & $3.79 \pm 2.67$ & $0.00 \pm 0.00$ & $3.31 \pm 2.80$ \\
Salinity $(\mathrm{Ms} / \mathrm{cm})$ & $5.30 \pm 2.42$ & $4.84 \pm 3.28$ & $4.48 \pm 1.30$ & $6.04 \pm 0.48$ \\
TN $(\mathrm{g} / \mathrm{kg})$ & $0.16 \pm 0.05$ & $0.18 \pm 0.04$ & $0.16 \pm 0.06$ & $0.18 \pm 0.04$ \\
$\mathrm{TP}(\mathrm{g} / \mathrm{kg})$ & $0.54 \pm 0.07$ & $0.56 \pm 0.08$ & $0.56 \pm 0.02$ & $0.56 \pm 0.09$
\end{tabular}




\begin{tabular}{lllll}
\hline Environmental variables & Based on traits & Based on traits & Based on structure & Based on structure \\
\hline SWC $(\%)$ & $13.68 \pm 2.43$ & $15.28 \pm 1.62$ & $12.96 \pm 1.15 \%$ & $15.31 \pm 1.92$ \\
\hline
\end{tabular}

Figure Caption

Figure 1 Study area and experiment plots set

Figure 2 Plot-scale hydrological connectivity indices.

Figure 3 PCA and grouping analysis based on the plant traits

Figure 4 Regression analysis between plant traits and hydrological connectivity indices

Figure $5 \mathrm{PCA}$ and grouping analysis based on the spatial structure. T-Number refers to the number of Delaney triangles in each plot, T-Area refers to the mean triangle area in each plot, T-Perimeter refers to mean triangle perimeter in each plot and SCI refers to the structure complex index of each plot.

Figure 6 Regression analysis between spatial structures and hydrological connectivity indices

Figure 7 RDA results of environment variables with plots distribution. Figure 7A gives the relation between plant traits and variables. Figure 7B gives the relation between spatial structures and variables.

Figure 8 Group regression between population density/spatial structure size and hydrological indices based on the biomass.
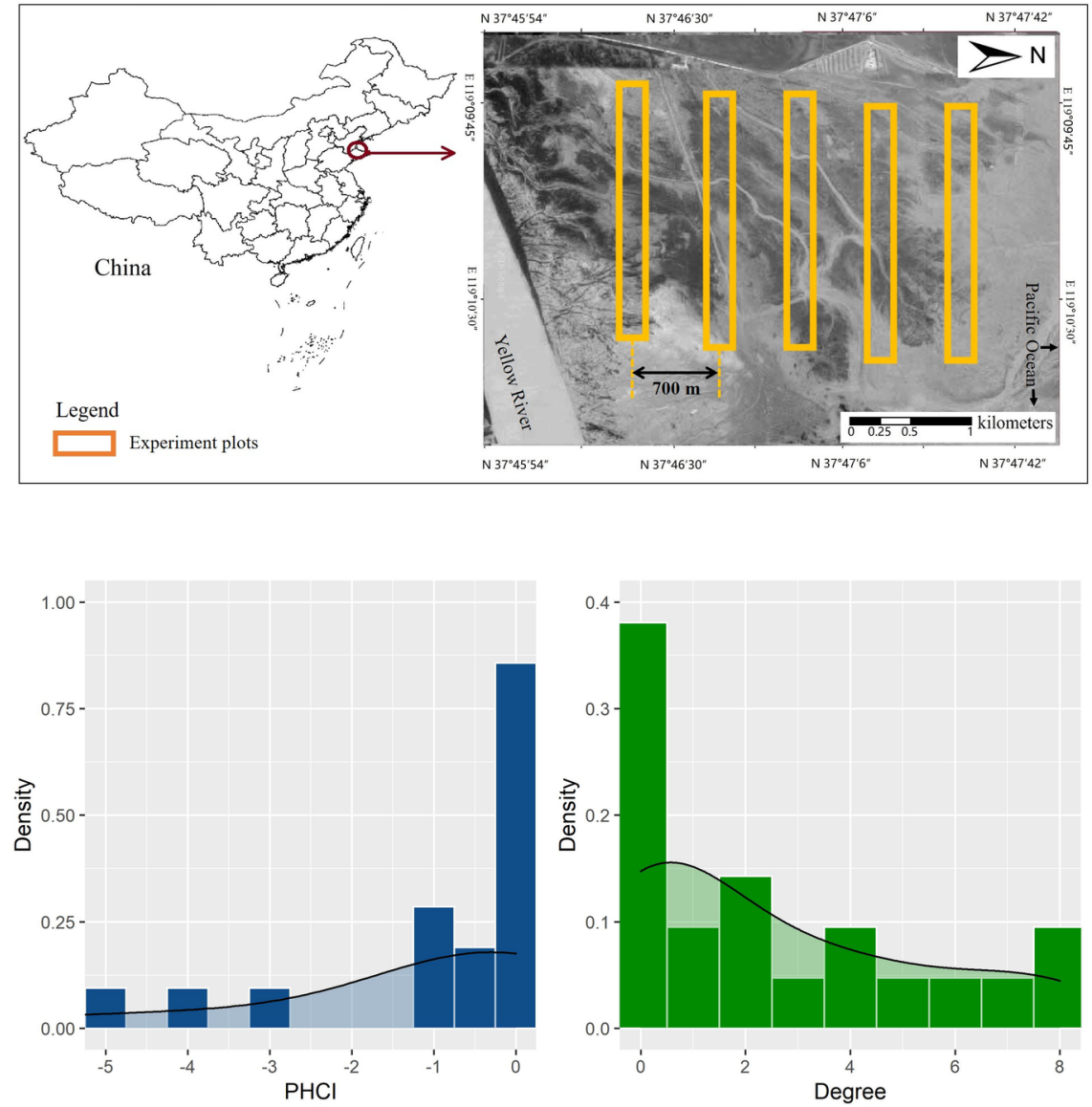

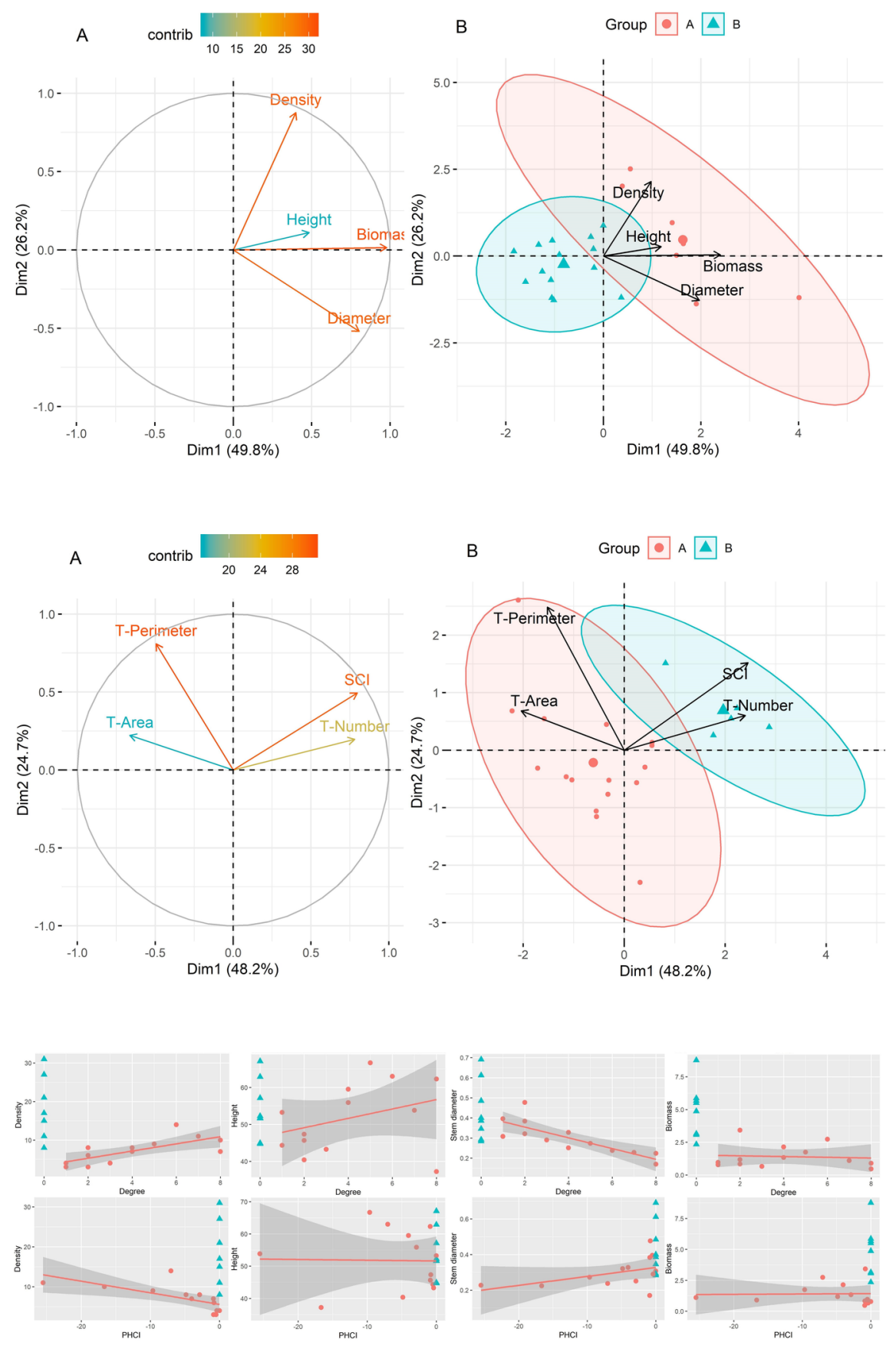

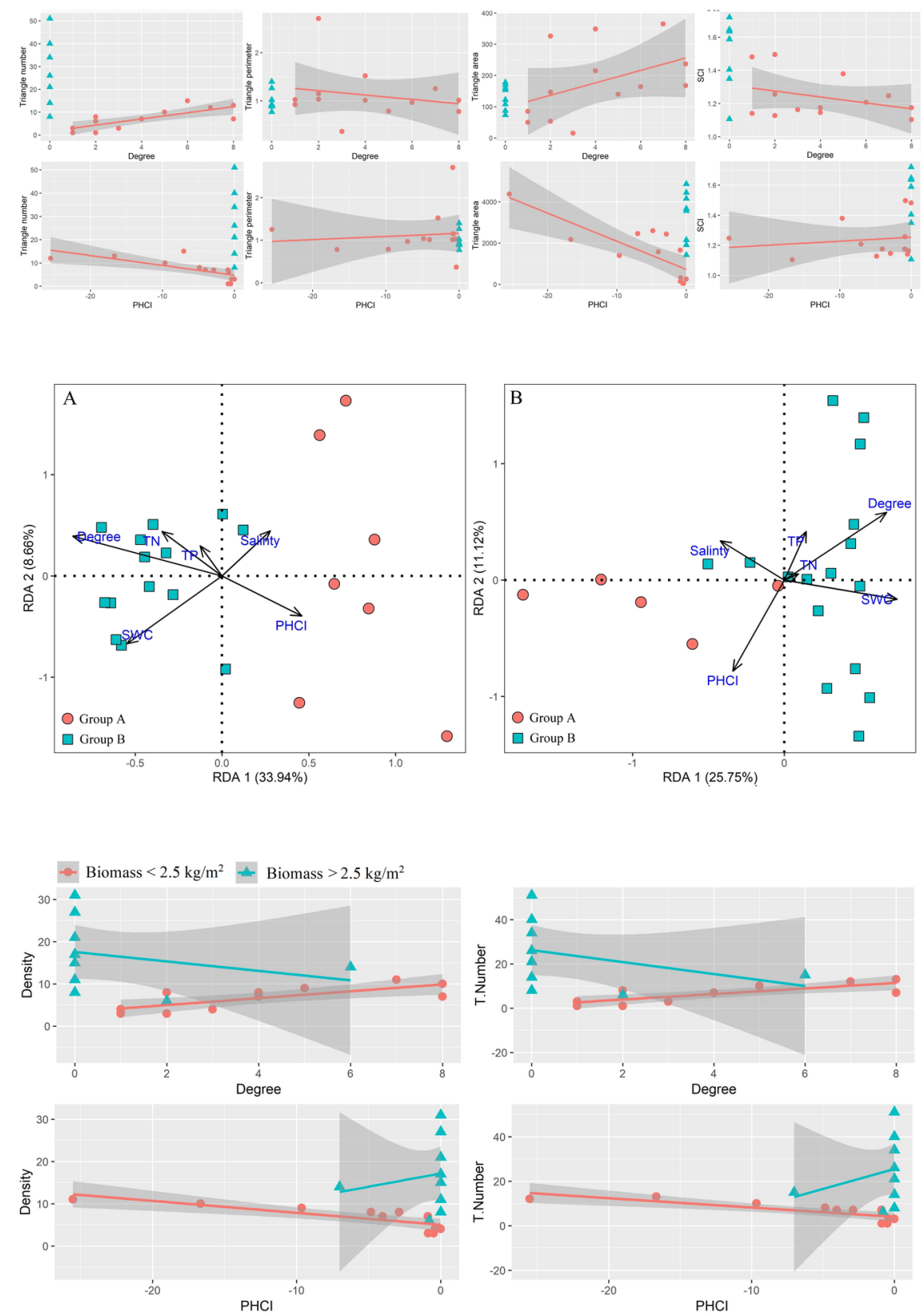